\title{
Closing the deal
}

\author{
Sadhana Chitale, Colm Lawler \& Scott Macfarlane
}

\section{A checklist for negotiating robust licensing agreements.}

niversities have long been viewed as important to the economic and social well-being of their communities, but in recent years expectations have changed. Universities are now expected, increasingly even mandated, by governments and other funders of research to play a more active role in economic development, especially by assisting in creating new companies, and ensuring that research funding eventually leads to products beneficial to the public. At the center of this activity is the university's technology transfer office (TTO), whose primary mission is to move research results from the non-profit laboratory into the hands of industry.

In reality, however, what the TTO is transferring is not 'technology' per se, but intellectual property (IP) in the form of patents, copyrights, proprietary materials and know-how-a 'transfer' that is accomplished through license agreements. A wellexecuted license creates a win-win situation, incentivizing a company to create new products, allowing the university to continue its research and ensuring all parties (including the innovators) receive a fair share of any economic benefits created along the way. A poorly executed license may not accomplish any of these goals.

In the following article, we present a simple checklist (Table 1) that is designed to help TTO professionals avoid catastrophic mistakes as they draft license agreements. We hope it will also be useful for faculty interested in understanding the best practices of TTOs. The goal of our checklist is to remind TTO profession-

Sadhana Chitale is at Office of Industrial Liaison, NYU Langone Medical Center, New York, New York, USA; Colm Lawler is at Partners HealthCare, Innovation, Cambridge, Massachusetts, USA; and Scott Macfarlane is at Technology Transfer, SUNY Upstate Medical University, Syracuse, New York, USA. e-mail: Sadhana.Chitale@nyumc.org, clawler1@ partners.orgorMacfarlS@upstate.edu als of critical things to check and verify before the license agreement is executed so that the license agreement does not fail when things go bad, or when things go much better than expected.

\section{Getting it done}

University licenses are harder to get right than one might think. Although it is common practice to start from an institutionapproved license template, many changes are made during the license negotiation to reflect unique aspects of the technology, industry and market, relevant regulations, and the company's business plans. While making these changes to the approved license template, there are numerous pitfalls and traps to avoid. Many changes are relatively innocuous, but some can have catastrophic consequences. The checklist in Table $\mathbf{1}$ is organized around ten issues. We discuss each of these in turn below.

\section{Internal due diligence}

Imagine granting an exclusive license to commercialize a technology and then discovering, years later, after the company has already invested millions of dollars, that you didn't actually own all of the rights to the technology. Or perhaps you granted a license to one company only to find out that your institution had already committed itself to granting an exclusive license to another. Disastrous mistakes like these result from a failure to identify everyone who has legal rights in a technology, such as when more than one research institution is involved with the IP being licensed, perhaps because an inventor initiated the research at one university but finished it at another, or because the invention resulted from a collaboration between multiple institutions. When more than one research institution has rights, an interinstitutional agreement setting out how the jointly owned IP will be managed is typically executed.
In other cases, the institution may have contractual obligations to one or more sponsors of the research. Non-federal funding sourcessuch as industry sponsors, foundations or individual philanthropists-often dictate the terms under which the IP sponsored can subsequently be licensed. Thus, for each piece of IP being licensed, a TTO professional must identify every research institution or sponsor that has, or could have, ownership rights. They must then review each sponsored research contract to make sure there are no obligations attached to the IP.

Once ownership and funding issues are under control, there are several other diligence matters to address, the most important of which is communicating the major terms of the deal to any internal stakeholders whose support will be needed for the deal to be successful, such as the inventors whose technology is being licensed, the person who will sign the license, relevant people in research administration and contract management, and any conflict-of-interest or commitment committees.

\section{Attention to detail in the license grant}

The license grant is the agreement's core. It delimits those rights being granted to the licensee and those rights being retained by the university. Even a single wrong word in this section can have profoundly negative repercussions.

There are a few important concerns here. The first is that the rights granted are limited to what was negotiated. The second is that the license is subject to appropriate conditions, including the government's rights if the research was federally funded, and appropriate compliance, such as paying what is due. A final concern is that inventors can continue to use the licensed technology themselves and allow their collaborators at other non-profit institutions to use it.

Making sure that the license grant is clear and unambiguous to all of those involved goes a long way to ensuring success. 


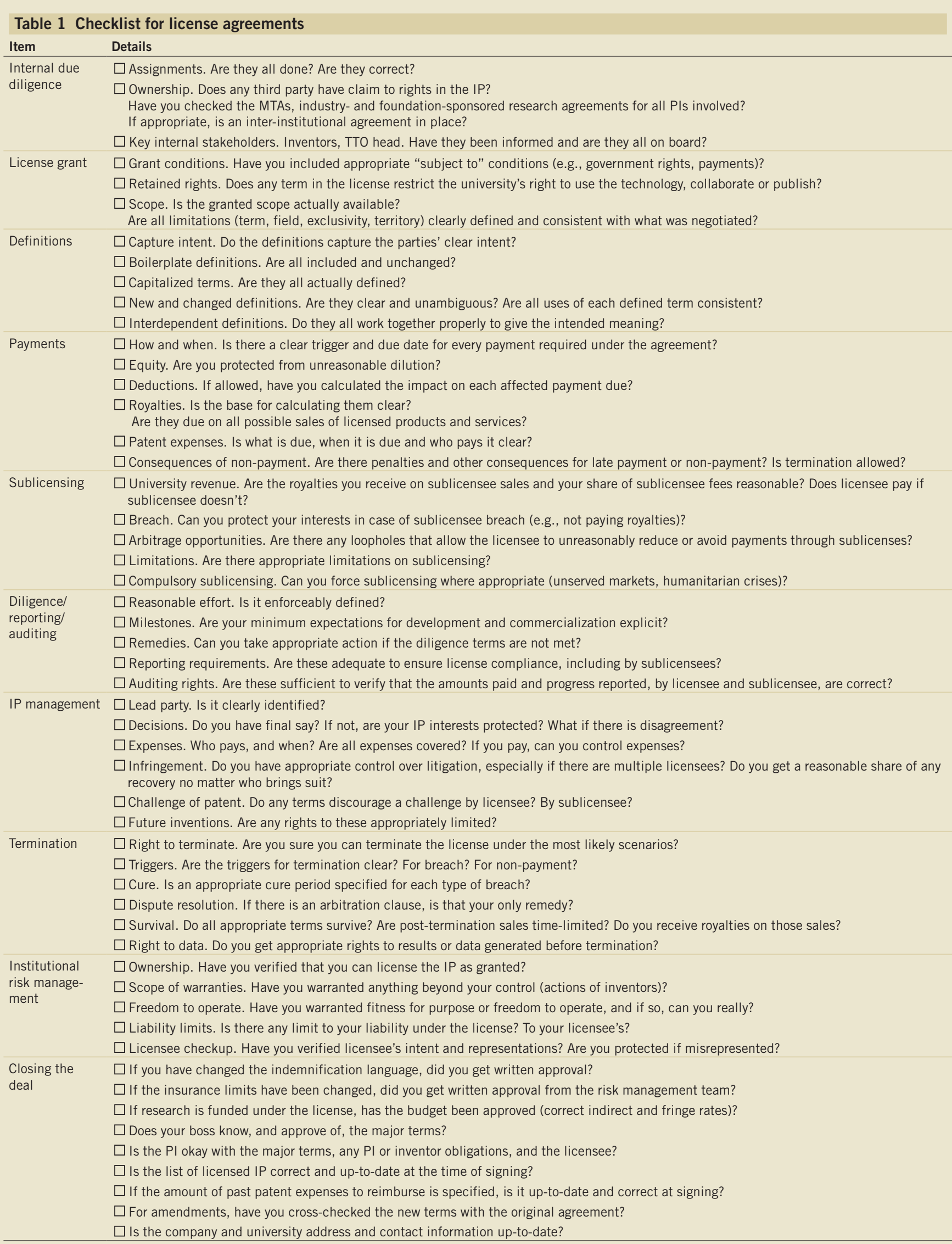

$\mathrm{PI}$, principal investigator; MTA, material transfer agreement. Checklist for licensing @ Sadhana Chitale, Colm Lawler, Scott Mcfarlane 


\section{Remove all ambiguity in definitions}

There is no room for ambiguity in license agreements, as ambiguity is an opening for disagreement and litigation. TTO professionals, both licensing managers and the attorneys who advise them, should wring every last drop of ambiguity from their license agreements. One way they do this is by creating 'Defined Terms'-these are usually designated by capitalization and, initially, quotation marks. Defined Terms are given explicit meaning in the agreement, which tells the reader how to interpret them.

Although the creation of Defined Terms can reduce ambiguity, it can also create its own problems, not least because the meaning of one Defined Term often depends upon the meaning of one or more other Defined Terms. The Defined Terms should thus form a cohesive linguistic scaffold for the whole agreement, as they determine how a license agreement will be interpreted in the unfortunate event of a dispute. It is therefore essential that they are constructed in a way that unambiguously captures the intent of the parties and are used consistently throughout the contract.

\section{Who gets paid, when?}

Research institutions hope that their licensing efforts will generate income to support their research activities in addition to leading to the creation of products that benefit the public. Companies generally do the heavy lifting involved in commercialization and therefore receive the greater part of any resulting financial benefits. However, the university, as a source of the innovation and owner of the IP, also deserves a reasonable share of those financial benefits. The financial consideration section of the license specifies what share the university, and thus the inventors, will receive. In addition, because license revenue is a key metric of TTOs, the payment section is the part of the license most likely to be reviewed by stakeholders unfamiliar with the deal, such as trustees. It is therefore crucial for the TTO professional to get the payment section right.

Payments are usually divided into fixed and variable payments. Fixed payments, such as upfront and yearly fees, are due in set amounts by established dates, while variable payments, which usually include milestone payments, sublicensing fees and royalties, are due only upon the occurrence of certain events, such as achieving a development milestone or selling licensed products. When variable payments are due and how much will be paid must be clearly defined. The payment terms must also spell out things such as which exchange rate to use when calculating royalties due the university on sales

\begin{tabular}{ll}
$\begin{array}{l}\text { Table } 2 \text { Checklist for faculty } \\
\text { Aspect }\end{array}$ & Details \\
\hline IP & $\begin{array}{l}\text { Is a biological substance, material or other background IP acquired from another } \\
\text { sponsor or another third party being used? } \\
\text { Is any IP likely to result from this research that may need protection in the form of } \\
\text { patents or copyrights? }\end{array}$ \\
& $\begin{array}{l}\text { Will copyrighted material be used, such as software which has 'use' restrictions? If } \\
\text { yes, please provide below the name, owner and any use restrictions. }\end{array}$ \\
& $\begin{array}{l}\text { For sponsored research agreements, have you put your academic collaborators on } \\
\text { notice that some future IP might be the subject of an option granted to a sponsor? }\end{array}$ \\
\hline $\begin{array}{l}\text { External } \\
\text { collaborations and } \\
\text { sponsorship }\end{array}$ & $\begin{array}{l}\text { Will you need to collaborate with another university to conduct the research plan } \\
\text { sponsored by the company? }\end{array}$ \\
& $\begin{array}{l}\text { Are other sponsors supporting the research underlying the invention or asset? If } \\
\text { yes, please provide your TTO with the sponsor's name, the project account number } \\
\text { and other relevant information. }\end{array}$ \\
\hline $\begin{array}{l}\text { Contractual } \\
\text { obligations }\end{array}$ & $\begin{array}{l}\text { Will you or someone else from your laboratory consult for the company? If yes, have } \\
\text { you provided your TTO with a copy of this consulting agreement? }\end{array}$ \\
$\begin{array}{l}\text { Some sponsored agreements may require you and your laboratory members to sign } \\
\text { CDAs. Have you informed your laboratory members of this requirement? }\end{array}$ \\
$\begin{array}{l}\text { Have you informed the Conflicts Committee of your desire to engage in sponsored } \\
\text { research for a particular company? }\end{array}$ \\
\hline CDA, confidential disclosure agreement.
\end{tabular}

in another country and what happens if payments are late, or don't occur at all.

In addition, the university must retain a right to audit the books of a licensor to verify the accuracy of payments received. All of this and more has to be addressed to ensure that the university receives the financial rewards it has negotiated.

\section{Clarify sublicensing terms}

Sometimes the licensee is not the commercial entity, or at least not the only entity, that will be involved in the commercialization of licensed products. For example, the licensee's expertise may be in product development, and it may want to hand off sales and distribution to a company already established in the marketplace. Or, the technology can be used in products for several different markets, only one of which the licensee intends to develop. In these and other cases, the licensee may want to grant a sublicense to another company (the sublicensee).

Under a well-constructed agreement, the university's financial return will be similar whether the technology is commercialized by the licensee alone or with the assistance of a sublicensee, but if the sublicensing terms of the agreement are poorly constructed, the university may receive little or no financial benefit from sales by sublicensees. To prevent this and other adverse outcomes, license agreements must clearly state what rights may be sublicensed and to whom, how the university's share of sublicensing revenues is calculated and who is ultimately responsible for paying it, and what happens in case of a breach by the sublicensee. The license must also require that sublicensees provide sufficient information, either directly or through the licensee, for their activities, sales and compliance to be monitored.

Other considerations are whether university approval is required before sublicensees can themselves grant sublicenses (it typically is required), what happens if a third party wants to commercialize the licensed technology in a market the licensee is not addressing (compulsory sublicensing) and whether the licensee can be compelled to offer a reasonable sublicense to an organization addressing a crisis, such as the AIDS crisis in sub-Saharan Africa.

\section{Set diligence terms that outline objectives and milestones}

TTOs strive to license technology only to companies that are willing and able to bring products to market in a reasonable time frame. To ensure such timely commercialization, particularly by exclusive licensees, the agreement needs to spell out the university's expectations.

This is the purpose of the diligence terms, which lay out what the company must accomplish, and by when it must accomplish them, to maintain its license. These can include objectives that both the company or a sublicensee must achieve by specific dates, such as regulatory milestones or reaching certain sales levels, and general obligations, such as making good faith attempts to sell products in each major market. It is crucial that the license states what the university can do if the company doesn't meet its obligations, especially if it appears the company's commercialization efforts will ultimately fail. 
There is a second, equally important, part here: reporting obligations. Unless the licensee reports on its efforts and results, including sales revenue, the university will not know whether it is meeting its diligence obligations or paying the correct amount of royalties.

\section{IP management}

The value of a patent application being licensed will not be fully known until government patent offices have ruled as to whether it should be allowed to issue as a patent, and with what claims. To ensure that their full value is realized, patents must be properly managed. This may involve multiple actions and decisions over many years and incur substantial costs. It is therefore important that the agreement be clear as to how the university and its licensee will manage the licensed patents. Areas of particular interest include the following: who has the final say in any decisions that incur substantial cost, such as a patent filing; how to ensure effective communication between the parties and with the IP attorney when formulating and executing strategy or responding to government patent offices; who will control patent infringement lawsuits and responses to post-grant challenges; and how the costs of IP management will be handled. This last point, in particular, has become important in recent years as the costs of patent prosecution have risen substantially, and more early-stage investors in startup licensees balk at covering patent costs during the early stages of license agreements.

\section{Termination}

Contracts that do not address termination scenarios invite dispute, and potentially court disaster. Licenses of patent rights typically terminate automatically on the date the last licensed patent expires or goes abandoned, but universities must retain the right to terminate the agreement earlier if the licensee defaults on its major obligations, such as failing to make payments or achieve specified milestones; otherwise, the university can be stuck with a nonperforming, non-paying licensee.

In addition to allowing an exit when the licensee is in default, the termination clause must also specify how any data, materials and results generated through the agreement will be handled. For example, under a research reagent license, must the materials be returned or destroyed? In addition, the license should automatically terminate in the event of a licensee's insolvency or bankruptcy filing, or if that is not allowed by the bankruptcy court, should stipulate that the license cannot be transferred to any entity unwilling to assume or incapable of meeting the prior licensee's obligations. A well-drafted agreement also specifies what happens after termination, such as to remaining inventory, and ensures that terms protective of the university survive.

\section{Representations, warranties and institutional risk management}

Because the vast majority of university research is early stage, and most university IP is licensed 'as is', the ability and willingness of the institution to make substantial representations or warranties (in other words, provide 'guarantees') is extremely limited. Moreover, there is a strong desire to avoid exposing the institution to any product liability that could damage its financial standing or risk its endowment.

For these reasons, universities normally adopt conservative positions when making representations and warranties in their licenses, and also expect potential licensees to carry adequate product and general liability insurance coverage. And although TTOs have flexibility in negotiating many other terms of a license agreement, their ability to deviate from the standard representations and warranty terms is extremely limited and can generally be done only with prior approval of the university's general counsel, institutional risk manager and/or insurance provider. Although companies that have previously licensed university technology usually accept these terms as a 'given' of doing business with a university, first-time licensees sometimes push for changes. It is key that the TTO professional makes no representation or warranty in the license agreement that is not cleared in advance by the university.

\section{Final considerations}

A final thing-carefully read through the entire agreement one last time to make sure all the headings and subheadings, as well as any appendices, are consecutively numbered and correctly referenced within the contract, and that no inadvertent errors have been made. Many TTOs require that a 'second set of eyes' always review a contract before it is signed. This is often done by someone from the department who has responsibility for managing the license agreement after execution.

\section{Conclusions}

We hope that this article has helped shed light on what goes on behind the scenes at TTOs. For readers who are faculty scientists or principal investigators, we hope it makes clear that negotiating and executing a license agreement is akin to the experimental plans they design and execute - all steps must be followed and properly executed for everything to work, for even small errors can have disastrous consequences to the outcome. So that these readers can help licensing professionals draft more robust licenses, we have also designed a short checklist (Table 2) that explicitly identifies several important research-related considerations relevant to licensing agreements.

Executing license agreements is possibly the single most important activity a TTO engages in, but even the most experienced licensing professional can get lost in the maze of license negotiation and drafting, and make an error or omission that transforms an otherwise solid license agreement into one that may fail. We have tried in our checklist to identify the worst pitfalls and traps that licensing professionals and faculty can fall into during the licensing process, but there are surely some we missed. We therefore invite readers to share with us their 'favorite' pitfalls and traps and any which are particularly relevant to their institutions, so that we can add them to our checklist.

Ultimately, successful licensing involves hard work and careful attention to detail. We hope that this checklist contributes to improving the process for both those in the university licensing community and the faculty they serve.

\section{First Rounders Podcast:}

\section{Anu Acharya}

Anu Acharya is founder and CEO of Mapmygenome, a co-

founder of Ocimum Biosolutions, and a leading light for life science entrepreneurship in India. Her discussion with Nature Biotechnology covers the importance of mentorship, running a consumer genomics company, and grieving the death of a parent. http://www. nature.com/nbt/podcast/index.html 